\title{
Density and magnetic susceptibilities of Schist: preliminary subdivisions by the petrographic classification
}

\author{
Luiz Fernando Tabosa, Luciana Figueiredo Prado, Elder Yokoyama, Thiago Lima Mendes, University of Brasília.
}

Copyright 2019, SBGf - Sociedade Brasileira de Geofísica

This paper was prepared for presentation during the $16^{\text {th }}$ International Congress of the Brazilian Geophysical Society held in Rio de Janeiro, Brazil, 19-22 August 2019.

Contents of this paper were reviewed by the Technical Committee of the $16^{\text {th }}$ International Congress of the Brazilian Geophysical Society and do not necessarily represent any position of the SBGf, its officers or members. Electronic reproduction or storage of any part of this paper for commercial purposes without the written consent of the Brazilian Geophysical Society is prohibited.

\section{Abstract}

Petrophysics is the area of geosciences that studies the physical properties of rocks. Petrophysical properties depend of rock composition and environmental conditions during the rock formation. In the case of metamorphic rocks, petrophysical properties can be used to subdivide a type of rocks, e.g. schists. In this study we present an attempt of schists subdivision based on magnetic susceptibility and density values applied to a bootstrap statistic method. We used 26 samples collected at Tocantins Province, Brazil. Preliminary results show that the bootstrap method can be used to increase the database of one type of schist. The bootstrap data show that samples physical properties have a normal distribution. Constraints and perspectives of this study will be discussed.

\section{Introduction}

Petrophysics is the are of geosciences responsible for studying the physical properties of rocks, making a connection between geophysical and geological models. The most commonly used petrophysical properties are magnetic susceptibility, density and electrical resistivity. Usually these properties vary according to the type of rock in a range of values. There is no precise value for petrophysical properties, even when dealing with the same type of rocks. For example, metamorphic rocks present a significant variation of physical properties values that depend of the protolith and the pressuretemperature conditions of rock formation. By contrast, petrophysical values can be used to determine and separate the type of rock and, in case of metamorphic rocks, to estimate their metamorphic conditions. In this context,. this study will attempt to subdivide schists types by using two physical properties, density and magnetic susceptibility, and by comparing these features with the petrographic description.

\section{Method}

A total of 26 samples were used in this study. This sample group is formed by different types of schist classified as biotite-muscovite-quartz schist, chloritetremolite schist, serpentine-tremolite schist, garnetmuscovite schists, and graphite schists. The values of these properties are disposed in Figure 1. Petrographic description of the samples was compiled from a geological mapping project, occurred in 2015 in the region of Paraiso Tocantins - TO (it can be found at University of Brasilia archives).

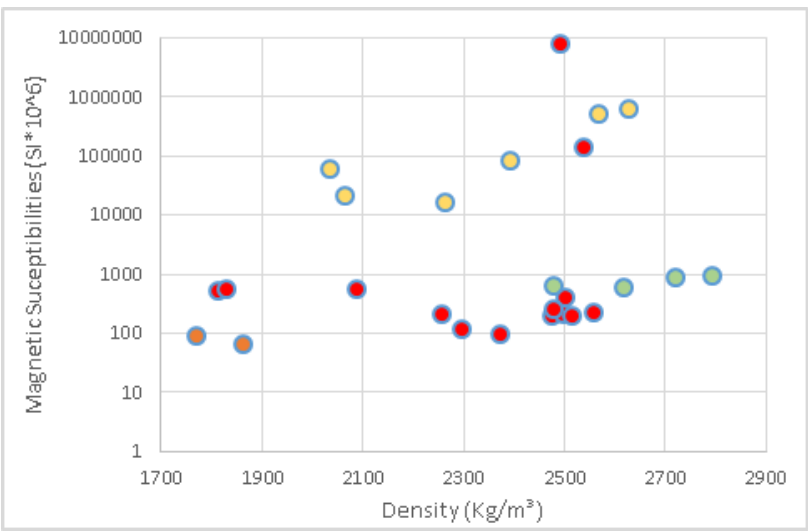

Figure 1: Samples disposed in a density vs. magnetic susceptibilities scatter plot, the color distinguished different petrographic classification (Yellow $=$ talc schist, tremolite serpentinite schist; Green= clorite schist, hornblendite schist; Red $=$ biotite schist; Orange $=$ Carbonous schist.

The data acquisition consisted in three phases: a. measurements of density data in a laboratory experiment; b. measurements of magnetic susceptibility; c. processing and data interpretation.

a. Measurements were based on Archie's law and consist of a series of weight measurements involving the samples value of dry mass, saturated in water mass, weight of the becker filled water. The next step was water immersion of the samples to obtain the variation of the water column (Figure 2). This was used to calculate the volume of the samples, and their densities, established on the equations (1). The unit used is $\mathrm{Kg} / \mathrm{m}^{3}$.

$$
d_{A}=\frac{m_{A}}{V_{A}}=\frac{m_{A} * d_{L}}{m_{L}}
$$


where :

$$
\begin{aligned}
& \mathrm{d}_{\mathrm{A}}=\text { sample density; } \\
& \mathrm{V}_{\mathrm{A}}=\text { sample volume; } \\
& \mathrm{m}_{\mathrm{A}}=\text { sample massa; } \\
& \mathrm{d}_{\mathrm{L}}=\text { liquid density }
\end{aligned}
$$

b. The magnetic susceptibility was acquired by using two apparatuses: MFK1-FA Kappabridge located at the University of São Paulo and MPP-EM2S + multiparameter located at the University of Brasilia. The parameter used is the volumetric susceptibility, which is dimensionless as classified in the SI.
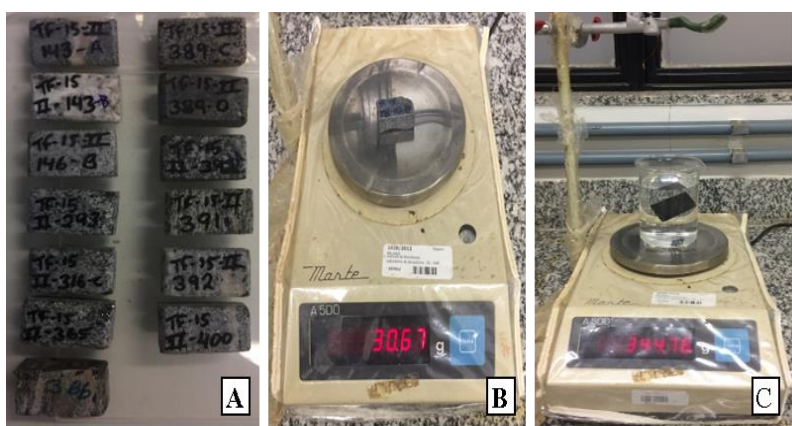

Figure 2: a) Samples used to acquire petrophisical data; b) dry mass of a sample being mesured with a balance; c) sample being immersed into water to obtain the values necessary to calculate density.

c. The data compilation was compiled in an Excel spreadsheet, containing physical parameters, type of the rock, and the code of the sample.

Figure 1 shows the distribution of physical properties according to the lithology defined in pertrographical analysis. The position of the samples was reviewed and the samples were grouped according to the mineralogical assemblages.

R-Statistics was used to do a resampling using the bootstrap method. The objective of resampling a bigger number of samples is to create a more accurate confidence interval $(\mathrm{Cl})$, based on the standard deviation $(\mathrm{R}$ "). We assume that the data behaves as a normal distribution.

The bootstrapping method used in each samples classification resulted in a histogram of the density of samples $v s . \mathrm{t}^{*}\left(\mathrm{t}^{*}=\right.$ bootstrap replicated values) and a dispersion graphic of $\mathrm{t}^{*}$ vs. Quantiles Standard Normal, the information of the standard error.

\section{Results}

The petrophysical data compilation and petrographic descriptions generated a dispersion graphic where the samples were discriminated by these criteria. The preliminary subdivision shows a relationship between both physical parameters and mineral assemblage of the samples. We suggest that rocks presenting the same classification with an anomalous value are that the geological setting of the formation, or a mistaken petrographic classification could influence these rocks.

The relation between these two physical properties can be associated to a normal distribution (Figure 3). The adjust for the distribution of $t^{*}$ for the standard quantiles show a linear relationship between the Density and Magnetic Susceptibilities, with a Confidence Interval of $95 \%(0.0987,0.8917$, values on the histogram) and a Standard Error of 0.2223 .

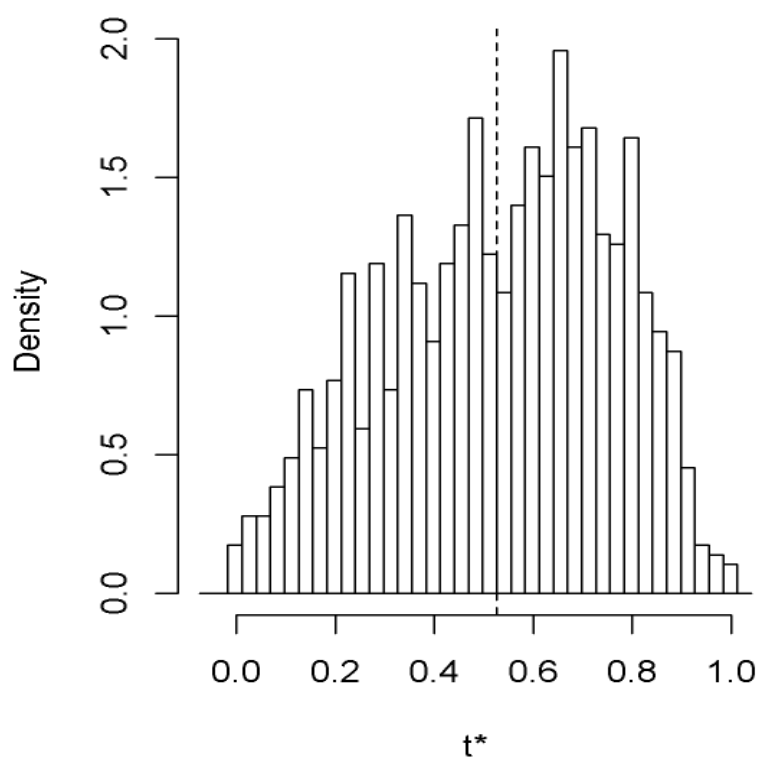

Figure 3: Histogram of the density of samples $v s$. $\mathrm{t}^{*}\left(\mathrm{t}^{*}=\right.$ bootstrap replicated values). Confidence interval between ( 0.0987, 0.8917).

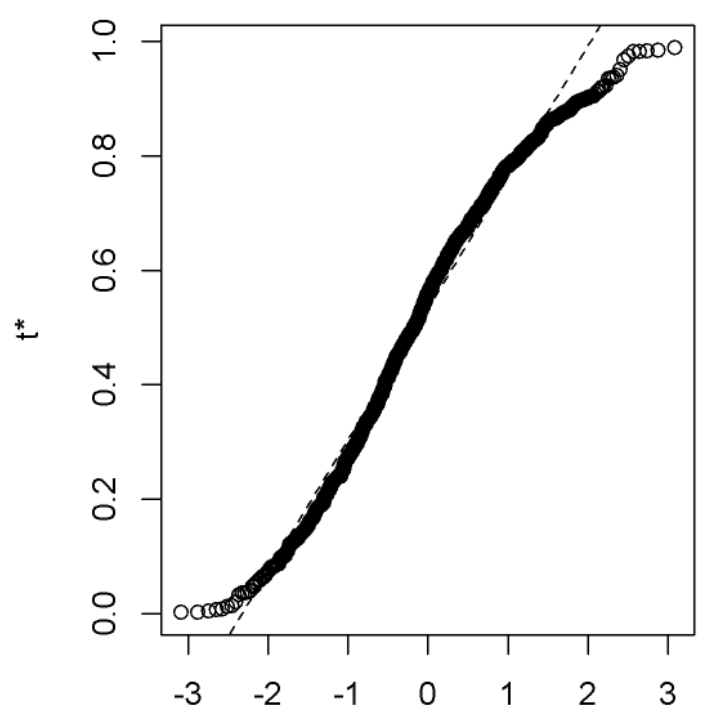

Quantiles of Standard Normal

Figure 4: Graphic of the sample distribution $t^{\star}$ for the Quantiles of Standard Normal. 


\section{Conclusions}

Data used in this study do not cover all types of schists, but provides a good understanding on how some sort of this schists behave, when their physical properties are studied in more detail. Results showed that the mineral assemblage subdivide and create a range of possibilities to each type of schist.

The bootstrapping technique help to set a better range, based on the $\mathrm{R}^{2}$, and to obtain the confidence interval. For a delimitation of a better range for each type of schists with a smaller error more samples are needed. A review on petrographic descriptions of anomalous values is required to improve the classification and subdivide the range found on literature for the different types of schist.

The next steps of this research aims to enlarge the number of samples, providing a larger range of schists types. We also aim to expand the research for other types of rocks such as granites, sienites, and quartzites.
Yang, T., Gao, Jintian, Gu, Zuowen, Petrophysical Properties (Density and Magnetization) of Rocks from the Suhbaatar-Ulaanbaatar-Dalandzadgad Geophysical Profile in Mongolia and Their Implications, 2013.

\section{Acknowledgments}

This study was financed in part by the Coordenação de Aperfeiçoamento de Pessoal de Nível Superior - Brasil (CAPES) - Finance Code 001, number 88887.314387/2019-00.

We are also thankful to the University of Brasilia, the Institute of Geosciences (IG-UnB), and to the Geochemistry laboratory (LaGeq-UnB) coordinated by Prof. Dr. Jeremie Garnier.

\section{References}

ANDRADE, J. C.; PAOLI, M. A.; CÉSAR, J. A Determinação da Densidade de Sólidos e Líquidos. Chemkeys. Disponível em: \&lt;http://objetoseducacionais2.mec.gov.br/bitstream/hand le/mec/11544/open/file/articlel.pdf. Acesso em: 28 de julho de 2018.

Davidson, A. C., Hinkley, D. V., Bootstrap Methods and their Application',, Cambridge University Press, 1997.

Hook, J.R. 2003. An introduction to porosity.Petrophysics.crain's petrophysicsal handbook https://www.spec2000.net/00-index.htm;

Monicard, R. P.1980. Properties of reservoir rocks: core analysis. éditions technip: Paris.

Ruotoistenmäki, T., Birungi, N. R. Petrophysical database of Uganda. Jornal of African Earth Sciences. 10617 - 39.

Schön, J.H., 2011.Physical properties of rocks, a workbook. Second edition, p. $17-73$.

Smithson, S. B., Densities of Metamorphic Rocks.

Geophysics, Vol. 36, NO. 4, p. 690-694, 1971. 